\title{
O explozie reflexivă asupra condiției umane: Ils refleurissent, les pommiers sauvages
}

\author{
Conf. univ. dr. Iuliana BARNA, \\ Universitatea „Dunărea de Jos” din Galați
}

\begin{abstract}
Ils refleurissent, les pommiers sauvage e un roman autoreflexiv care dezvăluie o lume paradoxală situată între iraționalitate şi dorinţa nestăvilită a omului de a introduce ordinea raționalã în univers, generând astfel o dramã existențialã profundă, prezentă frecvent în romanul modern. Descoperim aici un scriitor prolific, un spirit integrator, care are aspirația şi vocația de a surprinde totul: epoca în care trăieşte, spiritul lumii din care provine, sufletul uman.
\end{abstract}

\section{Key-words: literatură, oniric, artă, exil, real}

În concepția lui Virgil Tănase, scriitor autentic și inventiv, „romanul gravitează în lumea literelor asemenea unei planete: îşi are traiectoria sa, echilibrul său. Orice intervenție nu poate decât să-l smulgă gravitației care-1 susţine, pentru a-l azvârli într-un cataclism universal." ${ }^{17}$ Scriitura romancierului Virgil Tănase îşi însuşeşte toate formele de expresie, exploatează pentru sine toate procedeele şi nu se simte obligat să justifice folosirea lor. Romanul lui este unul al contemplaţiei, dar, în acelaşi timp, are darul de a se reinventa ori de câte ori începe o nouă istorie. „Tănase face parte dintre acei prozatori curioşi, atenţi să nu înţepenească într-o formulă sau într-un gen şi pentru care fiecare roman nou constituie un pas semnificativ în propria evolutie literară."18

M-am oprit asupra unei minunate cărți, apărută pentru prima dată la editura pariziană Ramsay în 1991, cu titlul original ${ }^{19}$ Ils refleurissent, les pommiers

\footnotetext{
17 Virgil Tănase, România mea, E.D.P., Bucureşti, 1996, 146.

${ }^{18}$ Dicţionarul General al Literaturii Române. Vol. VI (S-T), Academia Română-Institutul de Lingvistică, Editura Univers Enciclopedic, p. 637.

${ }^{19}$ Iniţial autorul ar fi dorit ca romanul să se numească Înfloresc vişinii sălbateci, (influenţat fiind de un foarte cunoscut cântec rusesc din acea vreme), dar renunţă la acest titlu, întrucât V.Tănase consideră că în franceză, griotte (vişină ) nu are rezonanţa lui pommier (măr) şi de aceea a optat pentru titlul Ils refleurissent,les pommiers sauvages. In 2015, romanul a fost editat ulterior laEditura Muzeul Literaturii Române în traducere: $A u$ înflorit iar vișinii și merii.
} 
sauvage, care m-a impresionat prin tehnica narativă construită atent, profund și misterios de un scriitor nobil.

Este o reflecţie asupra moralei catastrofice: cum trebuie să trăieşti când a face binele sau răul e totuna, când, luându-te valul, devii tu însuţi un element distrugător. Creatorul romanului imaginează o scenă în care actanții se află întro perpetuă metamorfoză, creând stări confuze. Marie, unica fiica a familiei Folga, rămâne însărcinată cu un anonim: „,sunt însărcinată cu un om pe care nu1 cunosc. El mă iubeşte, iar eu nu m-am născut încă. ... Când mă voi naşte, el va fi deja ucis" ${ }^{20}$. Moartea bărbatului necunoscut este reluată obsesiv pe mai multe planuri narative: iubitul se identifică cu un ofiţer nazist care se preschimbă în lup, în această ipostază găsindu-şi mai apoi sfârşitul; la un alt nivel acelaşi ofițer este ucis la ferma unde locuia împreună cu Marie şi cei doi copii ai lor, dar ca prin minune învie şi povesteşte propria moarte şi o ultimă variantă, portretizează un adolescent de 15 ani care suferă un final tragic, fiind omorât în curtea casei părinților Mariei de către patrioții francezi. Pe scurt, despre roman: metempsihoză, resurecție, reinventare.

Acţiunea este reluată după 20 de ani, când aflăm, retrospectiv, că Marie a născut un băiat pe nume Orlando, dat spre adopție, şi mai apoi s-a căsătorit cu un personaj politic important, Manuel, implicat in moartea celui pe care ea 11 iubea. Orlando este înfiat încă de la naştere de cuplul salvat de la moarte de către părinţii Mariei. Ajuns la vârsta de 23 de ani, Orlando, rămas singur căci mama sa şi-a schimbat identitatea pentru a putea supraviețui într-o lume devastată de ororile războiului, porneşte în căutarea tatălui sau ( adoptiv), pe care îl regăseşte bătrân şi singur. Sub ameninţarea că va fi exmatriculat de la Universitate, Orlando redactează o scrisoare prin care îşi denunţă tatăl de complot împotriva partidului la conducerea căruia se afla şi devine astfel instrumentul căderii propriului tată. Pentru a scăpa de nedreptatea autorităţii, Orlando se refugiază în satul în care s-a născut, încercând să dea de urma părinţilor săi naturali. Încă o dezamăgire: află că mama sa a murit în condiții tragice, iar soțul acesteia, presupusul lui tată, refuză să-l recunoască.

Drama personală a personajului masculin din romanul Ils refleurissent, les pommiers sauvage, dublează drama unei umanităţi întregi, a autorului însuşi, exilat într-o lume fără ieşire, într-un coşmar ce refuză să se risipească. De astă dată, eul auctorial îşi strigă neputinţa: « Mon Dieu, mais disais-je, si vraiment il a fallu que je vienne au monde, pourquoi ne m'avez-vous pas accorde le privilège d'être autre chose qu'un homme? et si je ne méritais pas d'être un arbre

${ }^{20}$ Virgil Tănase, Ils refleurissent, les pommiers sauvages, p. 46. 
ou une luciole, pourquoi ne m'avoir pas donné, au moins, la vie d'un animal, d'un de ces loups qui n'ont pour drapeau que leur sang répandu sur la neige? Pourquoi a-t-il fallu que je naisse parmi les plus méprisables créatures de la terre ? $»^{21}$

Ils refleurissent, les pommiers sauvage e o îmbinare reuşită de stiluri artistice, cuprinse în povestiri care se închid şi se deschid continuu, în neistovite paranteze, anulându-se şi înglobându-se, conduse de un povestitor ce se remarcă prin vocaţia ambiguităţii, într-un du-te-vino narativ suspendabil şi resuscitabil. De fapt, aici, «a povesti a devenit ceva imposibil.»²2

Este o proză analitică, speculativă, alcătuită cu ajutorul tehnicilor moderne şi postmoderne: introspecția conştiinţei şi a sufletului, autoanaliză, autoreflecție, psihologism, oniric pur, fragmentarism, biografism.

La Virgil Tănase construcția onirică se conturează astfel: obținerea unor sensuri noi, prin aranjarea după o logică proprie, a unor bucăți de real; în vise, persoanele concrete, perfect identificabile, se întâlnesc în situaţii cunoscute, deşi ele n-au trecut niciodată prin acele locuri. Romanul analizat surprinde prin contrastul pregnant dintre viziunea naivă şi copilăroasă a Mariei asupra dragostei şi ororile de neînchipuit ale războiului, pe care îl descrie cu o forţă de sugestie impresionantă: „, des vieillards expirent empalés sur des baionettes leur sortant par la nuque ou par l'œil...; des jeunes femmes nues dont on a écarté les jambes jusqu'à en déchirer le ventre ont été clouées sur les parois; ... les boyaux jetés au plafond, comme des serpentins, se sont accrochés aux lustres de Venise....la mer n'est plus qu'un océan de pus aux vagues ourlées d'une mousse sanguinolente, rose....".23

${ }^{21}$ Virgil Tănase, Ils refleurissent,les pommiers sauvages, p.125: „Dumnezeule, îmi spuneam eu, dacă a fost într-adevăr necesar ca eu să vin pe lume, de ce nu mi-ai acordat privilegiul de a fi altceva decât un om? şi dacă nu meritam sa fiu un arbore sau un licurici, de ce nu mi-ai dat măcar viaţa unui animal, a unuia dintre acei lupi, având ca drapel sângele lor răspândit pe zăpadă? De ce a trebuit să mă nasc printre cele mai demne de dispreț ființe din lume?..." (traducerea mea)

${ }^{22}$ A. Robbe-Grillet, Pour un nouveau roman, Éditions de Minuit, Paris, p. 37.

${ }^{23}$ Virgil Tănase, Ils refleurissent, les pommiers sauvages, p. 87: „... bătrâni murind împunşi de baionete care le străpung ceafa sau ochiul [...] femei goale cărora li s-au desfăcut picioarele până ce le-a crăpat abdomenul [...] intestine aruncate pe plafon, ca nişte serpentine, s-au agăţat de lustrele de Veneţia [...] marea nu mai este decât un ocean de puroi tivită de o spumă sângerândă." (traducerea mea) 
Intriga, clădită pe ambiguități şi răsfrângeri modificate ale realității, ar putea fi rezumată în doar câteva rânduri : Marie, o tânără adolescentă, se îndrăgosteşte nebuneşte de un ofiţer german, această relaţie devenind sursa tuturor întâmplărilor nefericite din viața ei. Tatăl ei, director de spital, este ucis deoarece fusese acuzat de trădare: ascunse un inamic în pivnița casei. Marie se vede nevoită să-şi croiască singură un drum în viaţă, complet neajutorată, alături de Orlando, rodul dragostei dintre ea şi ofițerul nazist. Întâlnim la Virgil Tănase aceeaşi tehnică de reinventare a romanului şi de astă dată cultivată oniric.

Iată ce ne comunică romanul: Marie, unica fiica a familiei Folga, asistă într-o noapte la venirea pe lume a celor trei pui a propriei cățele. Este momentul declanşator al vârtejului oniric. Simte cum burta i se îngroaşă, are simptomele unei femei pe cale sa nască. Marie nu ştie ce i se întâmplă, doar că : „azi-noapte parcă a trecut un lup prin curtea noastră". Este lupul micromotiv cu funcţiune specifică în proza onirică ? Credem totuşi, că figura zoomorfă nu poate fi decât o obsesie auctorială, a cărei desluşire e greu realizabilă şi în mod cert ține de regimul oniric.

Marie este însărcinată cu un bărbat pe care nu-l cunoaşte încă : „sunt însărcinată cu un om pe care nu-l cunosc încă. El mă iubeşte, iar eu nu m-am născut încă. Când mă voi naşte, el va fi deja ucis". Tema nenăscutului este reluată frecvent şi în teatrul lui Virgil Tănase. Acțiunea continuă pe axa întrepătrunderii realului cu imaginarul, legătura cauzală fiind ignorată, reluarea diegezei se va face diferit, cu un alt aport de informaţii, dar pentru aceeaşi întâmplare.

Vocea auctorială este rareori introdusă direct, păstrându-se aproape în rezervă, notând neutru şi spectacular desfăşurarea acţiunii, fiind dublată de cea a unui narator intern, iubitul Mariei, şi în ultima parte a romanului, de Orlando, fiul acesteia. Portretul eroului necunoscut se reflectă în ochii superbi ai Mariei, marea sa iubire. ${ }^{24}$ Remarcăm tehnica clasică de conturare, de sculptare a profilului unui personaj. Astfel, trăsăturile fizice ale iubitului Mariei sunt supuse privirii ei:" gâtul, umărul rotund şi, aproape imperceptibile, urmele tari ale muşchilor [..]. Părul negru, moale, umbrind ochii de un albastru electric[...].Sprâncenele desenate cu compasul. Bărbia rotunjită, crestată de un şanț. Chipul oval, de o rigoare clasică. Buze cărnoase, cea de jos uşor răsfrântă, gata să izbucnească sub vitalitatea unui sânge exuberant..." .( p.43).

Urmând itinerariul romanesc, se pare că facem cunoştință cu un narator intradiegetic care nu dă explicații, nu caută motivații, ci pur si simplu prezintă o

24 Virgil Tănase, Ils refleurissent, les pommiers sauvages, p. 43 
lume de oameni singuri care se întâlnesc şi se despart, se caută şi fug de ei înşişi, fiind nevoiţi să facă faţă unei provocări neaşteptate: dragostea. „Când eram tânăr, visam să te întâlnesc. Atingându-te cu privirea, mă simt învăluit de un sentiment straniu, cel al cuiva care se regăseşte, întâmplător, într-o casă izolată în plin câmp, într-o noapte furtunoasă. Neputând să doarmă, încolţit de căldura apăsătoare, pe întuneric, se duce la fereastră; o deschide; simte revărsându-se asupra lui imensa linişte a nopții; mase de aer obscure, umede, electrice, freamătă ; sângele îi este biciuit de unde imperceptibile pentru ochi, pentru epidermă, unde care poartă la sânul lor ciocnirea cu acele obiecte enorme, cu acele ființe imense pe care le-au izbit în drum, în acele momente, se simte prezența tuturor acelor lucruri cu atât mai angoasante $\mathrm{cu}$ cât rămân mai misterioase: animale cosmice de o bestialitate nemaiîntâlnită, stele uriaşe si carnivore, conglomerate dintr-o altă materie, mai intensă decât a noastră"....( Ils refleurissent, les pommiers sauvage, p.34).

Textul oniric se naşte din permutarea unor microsegmente narative şi descriptive posibil referenţiale, articulate într-o construcție menită să răsune după legile poeziei. $\mathrm{O}$ astfel de literatură recurge la alte procedee decât cele uzitate până acum: suprimarea timpului povestirii, „spulberarea cronologiei, suspendare şi fragmentare narativă." ${ }^{25}$ Povestirea devine un modalitate de autocunoaştere, dar şi un substitut al dorinţelor frustrante.

„Situaţia mea este cea a unui acrobat extraordinar, internaţional, care, în timpul unei demonstrații în plin aer, într-o grădină publică, de exemplu, mânat de entuziasm, îşi părăseşte trapezul şi sare din creangă în creangă, depăşeşte apoi grilajul scuarului şi îşi continuă numărul în plină stradă, în oraş, agăţându-se acum de firele electrice, de jgheaburile de streaşină, de brațele întinse ale statuilor ecvestre, de antenele de televiziune..., sărind din balcon în balcon, agățându-se de tot ce se află la îndemână, chiar de baloanele de copii sau de serpentine, de pene, de confeti sau de frunzele moarte aduse de vânt. El parcurge astfel centrul şi periferia, aruncându-se în gol fără să ştie ce îl va salva în momentul saltului său."( p.44) (subl. mea)

Odată ce fuzionăm cu substanța epică din Ils refleurissent, les pommiers sauvage, e de datoria noastră să percepem fiecare moment al povestirii în două planuri: în planul naratorului, ,în orizontul lui obiectual semantic şi expresiv" şi în planul autorului, cel "care se exprimă în mod refractat în şi prin această povestire" ${ }^{26}$

${ }^{25}$ Jean Ricardou, Noi probleme ale romanului, Editura Univers, Bucureşti, 1988.

${ }^{26}$ Ion Vlad, Lectura romanului, Editura Dacia, Cluj Napoca, 1983, , pp. 241-242 
Scrisul reprezintă pentru naratorul lui Virgil Tănase un „examen cotidian al sănătăţii mentale, aşa cum este prelevat, în fiecare zi, sângele unor bolnavi pentru a li se supraveghea sănătatea". (p.79)

Firul narativ rătăcește în labirintul său, aproape fără limite, personajului central şi destinul său blestemat au ca premise nişte coincidenţe malefice ce anulează posibilitatea unei împliniri în plan sentimental. Fiorul dragostei este simţit până în profunzimea poeticului. Dominat de o societate cu valori morale periclitate şi convenţionalisme, ca urmare a procesului de tranziţie, personajul anonim din literatura lui Virgil Tănase, erou a cărui identitate rămâne sub semnul suspiciunii, creează pentru a putea supraviețui degradării un univers al său, menit să înnobileze natura umană. „Suntem nevoiți să ne construim menirea din cuburi de realitate pe care le putem arhitectura în o mie de chipuri la fel de legitime cât n-o cunoaștem pe cea a lumii, și a căror multiplicitate dă măsura incertitudinilor cu care trebuie să trăim". ${ }^{27}$

Invenţia romanească ne este reprodusă pas cu pas de inventatorul ei: „A trebuit să inventez un mod de a aluneca muzical între diferite naraţiuni. Conducând o poveste până în punctul în care ea se confundă cu alta, continuu urmărind-o pe aceasta din urmă, apoi construiesc ceea ce în muzică se cheamă modulațiuni" ${ }^{28}$ Scriitorul deține libertatea absolută de a se juca cu regulile literare, de a lăsa să răzbată negânditul, inimaginabilul, obligaţie fundamentală a artei literare.

Ils refleurissent, les pommiers sauvage (Au înflorit iar vișinii și merii) pare a fi un mozaic de secvențe aparent fără nici o logică, care se suprapun peste sfera cotidianului, dominat de real prin vestimentaţie, mentalitate, peisaj arhitectonic, ceea ce conferă coeziune întregului text literar.

Caracterul autentic al discursului romancierului şi dramaturgului Virgil Tănase ține de individualitatea sa; artistul creează opera sincer, spontan şi calculat totodată, altfel spus, autenticitatea sa constă în menținerea în plan literar a unui hazard cerebral. Și cum în anul 2015, romanul îmbracă mantia cuvintelor românești, dezgolindu-se de cele specifice țării de adopție, ne propunem într-un studiu viitor să analizăm noua formulă sau poate, dimpotrivă, confesiunea ascunsă până atunci în straturile profunde ale memoriei.

27 Virgil Tănase, Leapșa pe murite, Editura Adevărul Holding, București, 2011, p. 109.

${ }^{28}$ Idem, România mea, p. 152. 


\section{Bibliografie}

Antofi, Simona, General Dictionary of Romanian Literature - Obverse and Reverse Critical Reception, în Oana Cenac (coord., edit.), International Conference of Common Vocabulary/Specialized Vocabulary: Manifestations of Creativity of Human Language, 6-7 iunie 2014, publicate în volumul MANIFESTARI ALE CREATIVITATII LIMBAJULUI UMAN, 2014, p. 13-19, ISBN:978-606-17-0623-5, WOS:000378446400001,

https://apps.webofknowledge.com/full record.do?product=WOSEsearch mode=General SearchEqid=2ESID $=$ N1izysiav2ciPKZmp8PEpage $=1 \mathcal{E} d o c=3$.

Cenac Oana, Discurs ideologic în "Ateneu" 1965, Actele conferinţei internaţionale Lexic comun / Lexic specializat. Democratizarea cunoașterii" sau migrația lexicului specializat spre lexicul comun, ediția a X-a, Universitatea „Dunărea de Jos” din Galați, Facultatea de Litere, Centrul de Cercetare Comunicare interculturală și literatură, 19 - 20 mai 2017, publicată în Analele Universității „Dunărea de Jos” din Galați, Fascicula XXIV Lexic comun / lexic specializat, revistă indexată in bazele de date internaționale EBSCO: https://www.ebscohost.com/titleLists/cmscoverage.pdf, MLA (Modern Language Association, New York, www.mla.org) MLA International Bibliography \& Directory of Periodicals, CEEOL și Fabula. La recherche en littérature (www.fabula.org), anul X, nr. 2(18) /2017, Editura Casa Cărții de Ştiință, Cluj-Napoca, 2017, ISSN 1844-9476, p. 31-48.

Cenac Oana, General aspects of current political terminology, în Lexic politic - discurs politic, 2014, p.124-130, ISBN:978-606-17-0633-4, WOS: 000378358200007.

Ifrim, Nicoleta, Memory and identity-focused narratives in Virgil Tănase's 'lived book', CLCWeb: Comparative Literature and Culture (ISSN 1481-4374) http://docs.lib.purdue.edu/clcweb/, nr. 19.2 / June 2017, Purdue University Press,pp.1-10, accesibil la adresa http://docs.lib.purdue.edu/clcweb/vol19/iss2/4/, https://doi.org/10.7771/1481-4374.2942 WOS: 000404572300004.

Dicţionarul General al Literaturii Române. Vol. VI (S-T), Academia RomânăInstitutul De Lingvistică, Editura Univers Enciclopedic, 2007.

Ricardou, J. Noi probleme ale romanului, Editura Univers, Bucureşti, 1988.

Robbe-Grillet, A. Pour un nouveau roman, Éditions de Minuit, Paris. Tănase, V., Ils refleurissent,les pommiers sauvages, Editura Ramsay, Paris, 1991. Virgil Tănase, Leapșa pe murite, Editura Adevărul Holding, București, 2011.

Tănase, V. România mea, E.D.P., Bucureşti, 1996. Vlad, I. Lectura romanului, Editura Dacia, Cluj Napoca, 1983. 